\section{La cartografía social como posibilidad de reflexión colectiva en contextos de precarización de la vida}

\author{
María Isabel Escurra \\ Universidad Nacional del Centro de la Provincia \\ de Buenos Aires, Argentina. CONICET \\ mescurra@fch.unicen.edu.ar \\ (iD) orcid.org/0000-0003-2100-6287
}

Inés Rosso

Universidad Nacional del Centro de la Provincia

de Buenos Aires, Argentina

irosso@fch.unicen.edu.ar

(iD) orcid.org/0000-0002-2650-7606
Sujetos y relaciones en extensión universitaria / Perspectivas
RECEPCIÓN: 24/04/20

ACEPTACIÓN FINAL: 12/06/20

\section{Resumen}

Reflexionar en torno a la construcción de metodologías territorialmente situadas resulta primordial al momento de pensarnos en la práctica extensionista. El Proyecto de Extensión "Nuestro Mapa. Diagnóstico participativo por medio de cartografía social" nos ha obligado a transitar debates que consideramos importantes compartir a la luz de la experiencia y de sabernos parte de un proceso de construcción colectiva de conocimiento que, con sus aciertos $y$ embates, se logró constituir y desarrollar en tramas complejas donde la precarización de la vida y la desciudadanización han adquirido una papel significativo en las últimas décadas. La cartografía social en esta experiencia se ha posicionado como una posibilidad de expresión y transformación en la que la interdisciplina ha cumplido un rol protagónico que es preciso desentrañar. Se presenta como resultado de este proyecto la sistematización envuelta en el desafío que nos propusimos al tornarla también participativa, constituyéndose en la intención de cerrar y de seguir trazando posibles caminos a transitar hacia la reivindicación de derechos en el contexto urbano.

Palabras clave: cartografía social; extensión universitaria; territorio; precarización de la vida
Social mapping as a possibility for collective reflection in contexts of precariousness of life

\section{Abstract}

Reflecting on building territorially situated methodologies is essential when thinking about extension practice. The "Nuestro Mapa. Participatory diagnosis through social mapping" Extension Project has forced us to go through discussions that we consider important to share in the light of experience and knowing that we are part of a process of collective construction of knowledge, which, with its successes and mistakes, managed to constitute and develop complex lattices where the precariousness of life and de-citizenization have acquired a significant role in recent decades. Social mapping in this experience has positioned itself as a possibility of expression and transformation in which interdisciplinarity has played a leading role that must be unraveled. The systematization involved in the challenge that we set out to make it also participatory are presented as results of this project, constituting the intention to close and continue tracing possible paths to travel towards the vindication of rights in the urban context.

Keywords: social mapping; university extension; territory; precariousness of life
Cartografia social como possibilidade de reflexão coletiva em contextos de precarização da vida

\section{Resumo}

Refletir sobre a construção de metodologias situadas territorialmente é essencial quando se pensa em prática de extensão. O Projeto de Extensão "Nuestro Mapa. Diagnóstico participativo através da cartografia social" nos forçou a passar por debates que consideramos importantes de compartilhar à luz da experiência e sabendo que fazemos parte de um processo de construção coletiva do conhecimento que, com seus sucessos e erros, conseguiu se constituir e desenvolver em tramas complexas, onde a precarização da vida e a descidadanização adquiriram um papel significativo nas últimas décadas. O mapeamento social nessa experiência se posicionou como uma possibilidade de expressão e transformação na qual a interdisciplinaridade desempenhou um papel principal que é preciso desvendar. A sistematização envolvida no desafio que propusemos tornando-a também participativa é apresentada como resultado deste projeto, constituindo a intenção de fechar e, ao mesmo tempo continuar delineando possíveis caminhos a percorrer na reivindicação de direitos no contexto urbano.

Palavras-chave: cartografia social; extensão universitária; território; precarização da vida

Para citación de este artículo: Escurra, M. I. y Rosso, I. (2020). La cartografía social como posibilidad de reflexión colectiva en contextos de precarización de la vida. +E: Revista de Extensión Universitaria, 10(12.Ene-Jun), 1-23. doi: 10.14409/extension.2020.12.Ene-Jun.9080. 


\section{A modo de introducción: la pretensión de situarnos territorialmente}

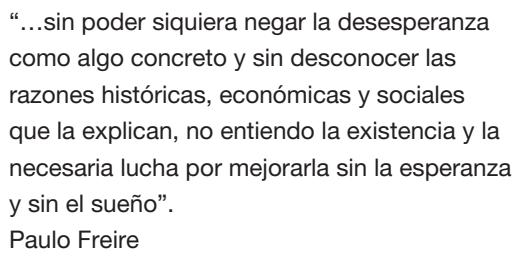

Pensar una contribución con relación a lo que esta revista nos plantea a través de los múltiples interrogantes que propone nos lleva a repensar algunas de las aristas de los procesos en los que venimos participando, teniendo en cuenta su historicidad y su complejidad. En el contexto actual, dada la complejidad social y el aumento exponencial de la desigualdad, es necesario reflexionar en torno a los procesos de desciudadanización y precarización de la vida así como a las posibilidades concretas de potenciar y/o acompañar procesos de reafirmación de derechos en territorio, que permitan la participación de los actores involucrados en la definición y resolución de sus problemas.

Entendemos que el desarrollo de prácticas participativas desde las organizaciones e instituciones implica la construcción desde abajo de procesos democráticos. Ello a través de la observación de cómo estos procesos inciden tanto en las organizaciones como en los sujetos, las familias y en las dinámicas territoriales. Y, en este sentido, resulta imprescindible trabajar junto con otres ${ }^{1}$ en consolidar la trama de participación de instituciones, organizaciones y pobladores y, al mismo tiempo, participar en la construcción de colectivos amplios, superando la atomización y apostando a generar una incidencia real en la definición de los problemas comunes.

En esta oportunidad presentaremos algunas reflexiones en torno al proceso de trabajo y resultados construidos en el marco del Proyecto de Extensión "Nuestro Mapa. Diagnóstico participativo por medio de cartografía social", anclado en la Facultad de Ciencias Humanas de la Universidad Nacional del Centro de la Provincia de Buenos Aires (UNCPBA), financiado por la Secretaría de Extensión de la misma Universidad y desarrollado entre 2018 y 2019 con participantes de los diferentes claustros de las carreras de Trabajo Social y Geografía.

Coincidimos con David Harvey (2008) en que es a partir de la década del 70 que se producen cambios en la acumulación del capital que conllevan la aparición de nuevas formas de acumulación por desposesión ligadas a proyectos societales neoliberales, que afectan de manera particular el espacio urbano.

"Vivimos cada vez más en áreas urbanas divididas, fragmentadas y proclives al conflicto. La forma en que vemos el mundo y definimos nuestras posibilidades depende del lado de la barrera en que nos hallemos y del nivel de consumo al que tengamos acceso.

1) Nota de la editora: el cambio de la vocal "a" o de la "o" por la "e" en la terminación de algunos artículos, pronombres o sustantivos que denotan un sentido binario varón/mujer obedece a una intencionalidad política del uso de un lenguaje no sexista que está impulsada por algunas expresiones de movimientos feministas y colectivos de LGTB. Así, en este caso, la expresión otres involucraría tanto a otros, otras, como a aquellas personas que no se sienten abarcadas por los géneros gramaticales establecidos. +E marcará en itálica aquellas expresiones que las autoras utilicen con el fin de respetar dicha intencionalidad siempre que no exista riesgo de anfibología. 
En las últimas décadas el giro neoliberal ha restaurado el poder de clase de las élites más ricas. (...) Los resultados de esta creciente polarización en la distribuci6n de la riqueza y el poder están indeleblemente grabados en las formas espaciales de nuestras ciudades, en las que se van condensando progresivamente fragmentos fortificados, comunidades cercadas y espacios públicos privatizados bajo una vigilancia constante." (Harvey, 2013, pp. 35-36)

En este mismo sentido, el autor expresa que, en estas condiciones, los ideales de identidad urbana, ciudadanía y pertenencia resultan mucho más difíciles de sostener, pero que también existen movimientos sociales urbanos que intentan superar el aislamiento y remodelar la ciudad de acuerdo con una imagen diferente de la lógica estrictamente empresarial. Ello mediante la reivindicación, abiertamente, del derecho de los desposeídos a su ciudad, su derecho a cambiar el mundo, a cambiar la vida y a reinventar la ciudad conforme a sus propios deseos.

"Solo cuando la política se concentre en la producción y reproducción de la vida urbana como proceso de trabajo fundamental del que surgen impulsos revolucionarios, será posible emprender luchas anticapitalistas capaces de transformar radicalmente la vida cotidiana. Solo cuando se entienda que quienes construyen y mantienen la vida urbana tienen un derecho primordial a lo que ha producido, y que una de sus reivindicaciones es el derecho inalienable a adecuar la ciudad a sus deseos más íntimos, llegaremos a una política de lo urbano que tenga sentido." (Harvey, 2013, p. 14)

Concebimos lo urbano, la ciudad, como producto de procesos histórico-sociales y económicos no ajenos a tensiones y conflictos de la sociedad que se tornan visibles en el territorio, en la forma que van tomando los barrios, las identidades, y en los espacios de resistencia y propuesta que se van construyendo. De este modo, si pretendemos conocer y caracterizar la situación barrial es necesario considerar procesos de transformación en sus diferentes niveles de concretización, los cuales generan situaciones de precarización de la vida en amplios sectores atravesados por los determinantes que ha impulsado el capitalismo en su fase neoliberal y flexible.

En las sociedades contemporáneas observamos procesos profundamente interrelacionados: precarización del trabajo, desempleo estructural y precarización de la vida de un gran número de la población. Procesos que se contraponen a la cada vez mayor concentración de la riqueza.

Antunes (2009) nos habla de una ofensiva generalizada del capital contra la clase trabajadora y contra las condiciones de trabajo propias del fordismo, una acción destructiva contra la fuerza de trabajo: precarización, intensificación, desempleo y prolongación de la jornada de trabajo. Siguiendo estos planteos, Fernández Soto y Tripiana (2009), en Argentina, en las últimas décadas, con el desenvolvimiento de una nueva fase de desarrollo capitalista caracterizado por procesos de repulsión de fuerza de trabajo y despojo de conquistas sociales, se ha reconfigurado regresivamente el mundo del trabajo, siendo la flexibilización la punta de lanza del capital en el proceso general de acumulación capitalista en su fase financiera. Emergieron y se consolidaron nuevas formas de dominación, pérdida de derechos laborales y subalternización, vinculadas a la extensión de la flexibilización y precarización laboral. 
Es real que estos procesos y vivencias de flexibilización y precarización, sumados a la precariedad de la infraestructura urbana y de los bienes públicos de protección social a los que se accede, condicionan la vida - y la muerte - cotidiana de grandes sectores de la población, acarreando situaciones de mayor o menor inseguridad social. No podemos visualizar la precariedad solo desde el ángulo de la inestabilidad económica ni de la inseguridad social, así como tampoco se la puede asociar a una mera cuestión individual. Sino que la entendemos con relación a las condiciones en las que se realiza el trabajo en nuestra sociedad, las condiciones de despojo que se viven, las condiciones del territorio que se habita y los espacios y formas de participación que se construyen y habilitan.

Así, si pensamos en cómo se resuelve la vida cotidiana, comprendemos que sectores numerosos de nuestra sociedad viven en entornos de precarización de la vida, y que estos se traducen en procesos de desciudadanización (Fleury, 1997). Lo que implica vivir material y subjetivamente desvinculados o vinculados frágilmente con la esfera pública y la trama de los asuntos comunes y colectivos de la sociedad. Resolviendo, cuando es posible, la cotidianeidad a través del mercado y/o debiendo demostrar su condición de pobreza para obtener beneficios sociales o asistenciales; y construyendo paralelamente procesos de organización popular que resisten al despojo, que (re)organizan aquello (des)organizado y atomizado por un Estado no presente o presente de manera insuficiente. En estos entramados se evidencian situaciones en las que los bienes públicos (salud, educación, vivienda, recreación, infraestructura urbana) dejan de ser percibidos como universales, como establecidos, como comunes, como derechos, para pasar a ser visualizados como mercancías, como productos y servicios a los cuales se llega a través del poder de compra o no se llega y hay que reconquistarlos.

Consideramos entonces que las formas en las que el capital se organiza y enfrenta sus crisis de acumulación agravan las expresiones de la cuestión social y también desencadenan respuestas de la sociedad y de la clase trabajadora en su movimiento de resistencia y de defensa de sus derechos (Raichelis, 2013). Lo urbano, la ciudad y el conflicto en torno a ella visibilizan estas cuestiones signadas por la desigualdad. Son las manifestaciones de la cuestión social las que se hacen visibles como malestares, necesidades y/o como problemas sociales.

Los problemas y las necesidades muchas veces aparecen como individuales, parcializados, fragmentados, sin raíces sociales, económicas ni políticas. Y esto no es casual ni natural, sino que se corresponde con un doble movimiento social que los deshistoriza y deseconomiza, y aparecen como cuestiones naturales, individuales, morales y/o inevitables. Como lo expresa Netto (1992), la intervención estatal sobre la cuestión social se realiza fragmentándola y parcializándola, lo cual nos posiciona frente a problemáticas particulares, recortadas, y hasta factibles de ser enfrentadas. La cuestión social es interpretada a través de problemas sociales cuya definición expresa construcciones sociales en las que impera una cosmovisión dominante de interpretar, resolver y organizar la sociedad (Fernández Soto, 2004) muchas veces lejana a lo que les ciudadanes desean. Allí es cuando las necesidades sociales pueden ser politizadas y, si así sucede, suelen transformarse en demandas e ingresan a la arena política (Fleury y Molina, 2000).

De este modo, resulta importante trabajar para problematizar los problemas sociales $\mathrm{y} / \mathrm{o}$ situaciones que nos vienen dados, lo cual requiere poseer la información suficiente para poder procesarlo situacionalmente y desde allí pensar estrategias que acompañen a los actores que, en situación, necesitan o desean revertirlos. 
Este artículo ha sido estructurado con fines analíticos, en un ir y venir que nos permite reflexionar y con la intención de compartir esas reflexiones, sentires y procesos. En un primer momento proponemos acercarnos a las particularidades de la ciudad de Tandil (provincia de Buenos Aires, Argentina) y de los barrios en los cuales desarrollamos las prácticas extensionistas, para luego comentar algunas cuestiones en torno a los desafíos metodológicos e interdisciplinarios que compartimos en estas instancias desplegadas desde la cartografía social y la interdisciplinariedad. En un tercer momento del trabajo proponemos reflexionar respecto de las estrategias de sistematización, partiendo de comprender los mapas como producto y como proceso e invitando(nos) a seguir construyendo metodologías participativas y situadas que problematicen la realidad y revaloricen el derecho a pronunciar el mundo que deseamos.

\section{Reconocer las particularidades de la ciudad y del barrio. Sujetos, procesos, políticas y desafíos}

Considerar las cuestiones anteriormente mencionadas implica el desafío de situar las prácticas extensionistas en un territorio, con dinámicas propias pero no ajenas a los determinantes y condicionantes sociales, económicos y políticos que hacen a la compleja situación actual. En este sentido, para analizar la situación local es necesario reconocer procesos de transformación en sus diferentes niveles de concretización que generan situaciones de privación social en amplios sectores de la ciudad de Tandil, donde el Proyecto "Nuestro Mapa" se desarrolló.

Tandil se caracteriza por ser una ciudad intermedia del sudeste de la provincia de Buenos Aires, con un crecimiento poblacional constante, y conforma un centro urbano dinámico. Según la clasificación propuesta por Vapñarsky y Gorojovsky (1990), estas ciudades son consideradas aglomeraciones de tamaño intermedio (ATIS) y, más precisamente, ATIS medias por estar dentro de la categoría que incluye de 50.000 a 399.999 habitantes (Linares, 2011), ya que en 2010, según el último Censo (INDEC), alcanzaba los 116.916 habitantes.

Siguiendo los planteos de Fernández Soto et al. (2012), el perfil productivo del partido de Tandil comienza a cambiar hacia mediados del siglo XX. La ciudad de Tandil ha combinado producción primaria con producción secundaria, lo que le ha dado un perfil industrial en el contexto de la región pampeana. Sin embargo, las transformaciones desde mediados de la década del 70 han erosionado este perfil industrial, reduciéndose el número de establecimientos (en un $40 \%$ ) y de la cantidad de obreros (50 \%) entre 1974 y 2004. Como consecuencia se observa una pérdida de importancia del sector industrial, reemplazado por un sector agrícola en expansión volcado a la especialización en determinados cultivos y por un creciente protagonismo del sector servicios. Las consecuencias sociales de este cambio son muy importantes, situación que se intensifica hacia fines de la década del 90 y que se expresa en las décadas siguientes en una ciudad cada vez más desigual, polarizada espacialmente y fragmentada.

Esta dinámica de polarización espacial fue consolidando transformaciones en el proceso de producción y de apropiación del espacio urbano, caracterizadas principalmente por la segregación y la fragmentación, aspectos que se expresan en la creciente expulsión hacia los márgenes de la población empobrecida y en el deterioro de las condiciones de integración y de calidad de vida urbana (Valente Ezcurra, 2018). 
La desigualdad para acceder a los equipamientos y servicios sociales básicos instaura en la construcción histórica de la ciudad una dinámica urbana de segregación territorial y social. Se advierten procesos desiguales de apropiación, por parte de la población, de los servicios y bienes sociales, los cuales también se presentan en la dinámica social de una manera estratificada, y eso muestra el resultado combinado de una oferta y apropiación de la misma altamente segmentada y desigual (Linares, 2008; Migueltorena y Linares, 2019). Esta situación se ve reforzada por la retracción de la intervención estatal desde el nivel central en la década del 90, que desliga al ámbito municipal y a la sociedad civil mediante procesos de transferencia, de hecho o de derecho, de responsabilidades históricas (Fernández Soto et al., 2012).

En cuanto a lo mencionado anteriormente, y teniendo en cuenta los aportes de estos últimos autores, reconocemos que en un contexto de mayor precariedad en las condiciones de trabajo y de vida de una gran masa de población surgieron organizaciones sociales con la intención de dar respuestas a esos problemas emergentes, al tiempo que otras organizaciones con una trayectoria histórica más extensa incorporaron distintas actividades frente a la emergencia. Este surgimiento responde tanto a iniciativas autónomas como al fomento de la descentralización estatal de la administración de recursos y la tercerización para la ejecución de políticas sociales, en tanto que las organizaciones oficiaron como "mediadoras"2 entre el Estado y la pobreza con alta presencia en los barrios de la ciudad de Tandil.

En este contexto, con la incorporación de un principio de subsidiariedad territorializada (Fernández Soto, 2009) las organizaciones de la sociedad civil aparecen con una especial participación en la ejecución final de las políticas sociales que el Estado dirige a los sectores más empobrecidos. Así, ciertas organizaciones e instituciones estatales con alta presencia en el territorio (escuela, centro de salud, centros comunitarios, sociedades de fomento, centros culturales, bibliotecas, entre otras) participan en el barrio como mediadoras en la relación Estado-pobreza,3 entendiendo que median en tanto los pobres se relacionan con el Estado a través de ellas.

En la situación de Tandil, la ciudad, y en ella el espacio barrial, van reconfigurándose como territorio donde se manifiestan los conflictos y también donde se materializan y/o hasta construyen las respuestas. Merklen (2010), en su análisis sobre los barrios populares, expresa que en ellos viven aquellos que sufren de déficit más o menos importantes de integración social y en condiciones más o menos severas de carencia material. Además, afirma que este punto de partida de déficit obliga a los habitantes a moverse sobre la base del territorio donde habitan, siendo el barrio un espacio en el que se refugian los desafiliados de la crisis de fines de siglo $\mathrm{XX}$, sustentados en solidaridades territoriales o locales que actúa como un seguro multirriesgo de los pobladores. La política de descentralización municipal que se motorizó para la ciudad de Tandil ha ido abonando a esta reconfiguración, al tiempo que las personas y las organizaciones fueron construyendo en los barrios entramados de sostén, no exentos de conflictos, ante la mayor precariedad y el empobrecimiento de quienes allí viven.

2) La Sociedad Civil puede ser concebida como mediación entre la estructura económica y la Sociedad Política. Esta formulación gramsciana destaca el vínculo de esta esfera con los intereses y proyectos de clase en disputa. Así la Sociedad Civil se concibe como el espacio en el cual los intereses de las clases y fracciones de clase se organizan y articulan políticamente para construir hegemonía o contra hegemonía. (Vieira de Almeida, 2006)

3) A fin de profundizar sobre la mediación de las organizaciones de la Sociedad civil entre Estado y pobreza véase Barrera (2013) 
En 2003, con la asunción del radicalismo en el gobierno municipal, liderado por Miguel Lunghi, se planteó la preocupación por desarrollar una gestión social eficiente y de proximidad con los sectores empobrecidos radicados centralmente en las zonas periféricas de la ciudad. Y se anunció un plan de descentralización y zonificación municipal que fue entendido como "una nueva forma de gobierno de la ciudad, intentando brindar respuestas eficaces a los problemas comunitarios mediante un mayor acercamiento entre el municipio y los vecinos" (Municipalidad de Tandil, 2004, p. 16).

La zonificación municipal implementada desde 2004 implicó la definición de recortes territoriales para la gestión de la ciudad de Tandil, desconcentrando la acción gubernamental a través de la Secretaría de Desarrollo Social a los diferentes barrios de la ciudad. El gobierno municipal señaló tres motivos principales para impulsar esta modalidad de gestión. El primero tiene que ver con el número de habitantes y extensión territorial que presenta esta ciudad, argumentando que el proceso de expansión de la ciudad va expresando territorialidades barriales diferenciadas. El segundo motivo se relaciona con la carencia de servicios en las zonas más periféricas de la ciudad y las desigualdades socioeconómicas, para lo que se entiende que se deben diseñar estrategias diferenciales de acción y que evidencia una clara fragmentación territorial de la ciudad (Municipalidad de Tandil, 2004, p. 31). El tercer motivo, íntimamente vinculado con el segundo, se refiere a las posibilidades de acceso de la población residente en los barrios periféricos. Se construyó así un discurso oficial que pretendió revitalizar el rol del municipio en la planificación y gestión de la política social local (Fernández Soto y Tripiana, 2011; Fernández Soto et al., 2012; Fernández Soto et al., 2015).

A este respecto, el intendente, en la presentación del documento oficial con la "Propuesta de descentralización y zonificación municipal", expresaba la importancia de la planificación a mediano y largo plazo y señalaba los principales componentes que definirían la política social municipal desde 2004: descentralización y zonificación municipal, interacción y acuerdos con organizaciones sociales barriales, constitución de centros comunitarios como espacios de referencia municipal en los barrios de la ciudad y su complementación con los Centros de Salud ya existentes (Municipalidad de Tandil, 2004).

Los barrios donde desarrollamos los procesos de extensión son Villa Gaucho, Palermo y Selvetti, y se localizan hacia el este de la planta urbana de la ciudad de Tandil, coincidiendo su límite sur con la Ruta Nacional № 226. En la división administrativa que define la Municipalidad de Tandil en el proyecto ya nombrado, tales barrios componen lo que se denomina Zona 3. Esta zona contaba, para 2010 con una población de 6885, según el Censo Nacional de Población, Hogares y Viviendas (INDEC), distribuida en las siguientes franjas etarias: 1578 personas de 0 a 11 años, 900 de 12 a 18, 3948 en el rango de 19 a 64 años, y 459 de 65 y más. Según el mismo censo, poseía 1965 viviendas y 2047 hogares. A fin de evidenciar la situación socioeconómica que caracteriza a estos barrios, se presentan a continuación algunos de los indicadores que elabora el INDEC que consideramos representativos, ya que dan cuenta de la compleja y diversa realidad que atraviesa la comunidad en cuantoa sus condiciones materiales esenciales.

En el primer caso se trata del concepto de Necesidades Básicas Insatisfechas (NBI), el cual permite "la delimitación de grupos de pobreza estructural y representa una alternativa a la identificación de la pobreza considerada únicamente como insuficiencia de ingresos" (INDEC, 2012, p. 306). Por medio de este indicador se pretenden identificar dimensiones de 
privación absoluta, entendiendo la pobreza como el resultado de un cúmulo de privaciones materiales y considerando que un hogar es pobre si sufre al menos de alguna de las siguientes situaciones: vivienda de tipo inconveniente (habitaciones de inquilinato, precaria, no destinada a fines habitacionales $u$ otro tipo), viviendas sin cuarto de baño, hacinamiento crítico (más de tres personas por cuarto), hogares con niños en edad escolar (6 a 12 años) que no asisten a la escuela, y con cuatro o más personas por miembro ocupado y en los cuales el jefe de hogar tiene bajo nivel de educación (dos años o menos en el nivel primario).

El mapa que sigue representa los hogares con al menos un indicador de NBI en la ciudad de Tandil. En el polígono seleccionado se puede reconocer el área de trabajo -Zona 3-, cuya mayor superficie posee entre 6 y casi $11 \%$ de hogares en dicha situación (sector coincidente con la cercanía a la Ruta Nacional № 226 y la Avenida Actis, arteria de ingreso al sector noreste de la ciudad), proporción que se encuentra muy por encima de la media de la ciudad (3,16\%). Resulta llamativo el contraste que se destaca en el centro de la zona, que, si bien no está en el segmento de radios censales con mejores situaciones, oscila entre un 1 y un $3 \%$. Tal particularidad responde a que allí se encuentran los barrios sociales planificados como AMEMT I y II, PROCASA II, FALUCHO XXII, FONAVI y otros de autoconstrucción, en los cuales se garantizan, por medio del financiamiento estatal directo o indirecto, algunas condiciones constructivas en lo que hace a los materiales y el acceso a servicios básicos.

Figura 1: Hogares con al menos un indicador de NBI. Tandil, 2010

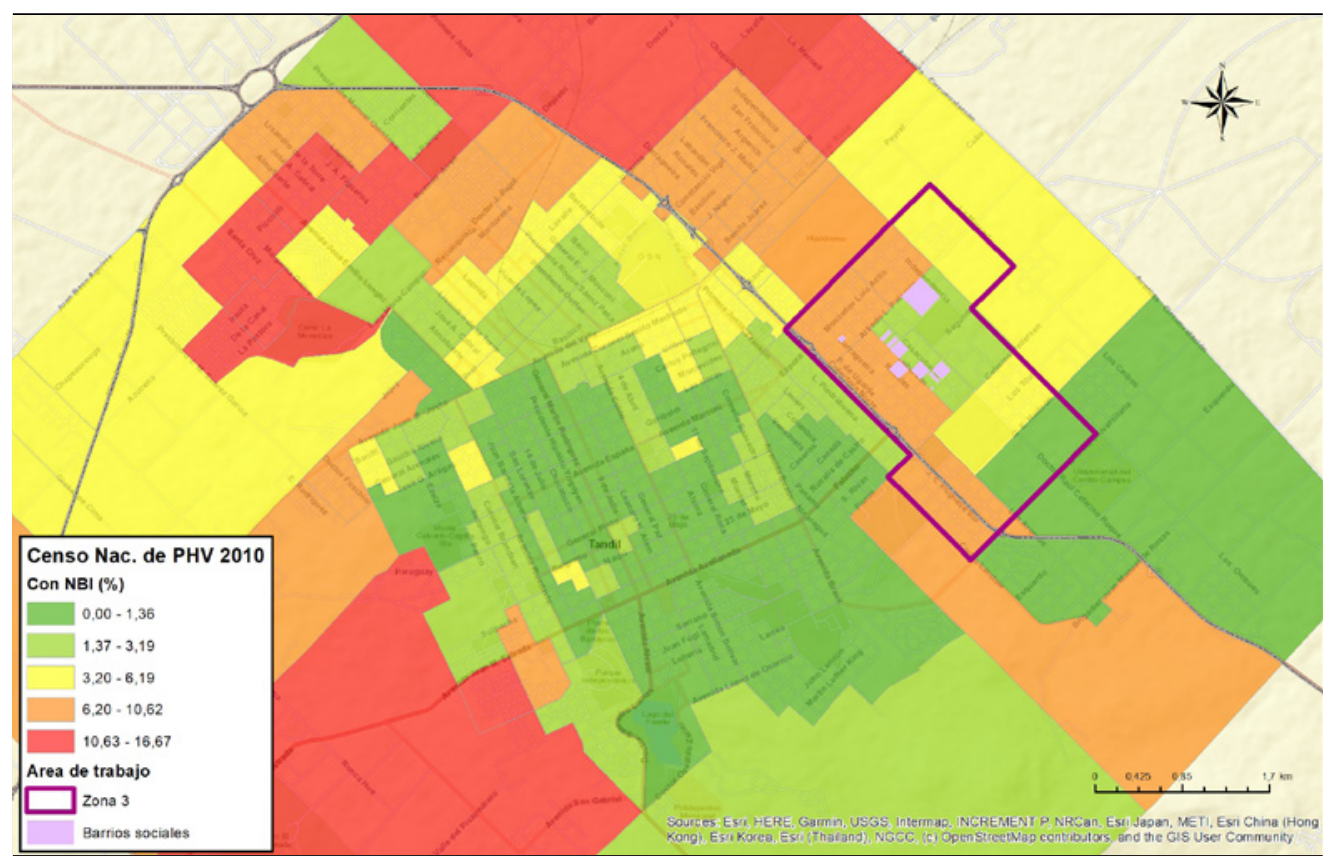

Fuente: elaboración propia sobre la base del Censo Nacional de Población, Hogares y Viviendas. INDEC, 2010.

En el segundo caso, consideramos importante representar la variable de Calidad constructiva de la vivienda - INCALCONS - , cuyo indicador "se construye a partir de la calidad de los materiales con los que está construida la vivienda y las instalaciones internas a ser- 
vicios básicos (agua de red y desagüe) de las que dispone" (INDEC, 2013, p. 5), ya que nos permite dar cuenta efectivamente de las deficiencias materiales de la vivienda y, por lo tanto, de las condiciones de precariedad en las que la población vive. Los resultados se clasifican en tres categorías: a) calidad satisfactoria, que refiere a las viviendas que disponen de materiales resistentes, sólidos y con la aislación adecuada y, a la vez, disponen de cañerías dentro de la vivienda y de inodoro con descarga de agua; b) calidad básica, no cuentan con elementos adecuados de aislación o tienen techo de chapa o fibrocemento y, al igual que el ítem anterior, cuentan con cañerías dentro de la vivienda y de inodoro con descarga de agua; y c) calidad insuficiente, que engloba a las viviendas que no cumplen ninguna de las dos condiciones anteriores. Se presentan a continuación los datos según viviendas cuyas características las posicionan en las categorías básica e insuficiente.

Figura 2: Calidad constructiva de la vivienda, categorías Básica e Insuficiente. Tandil, 2010

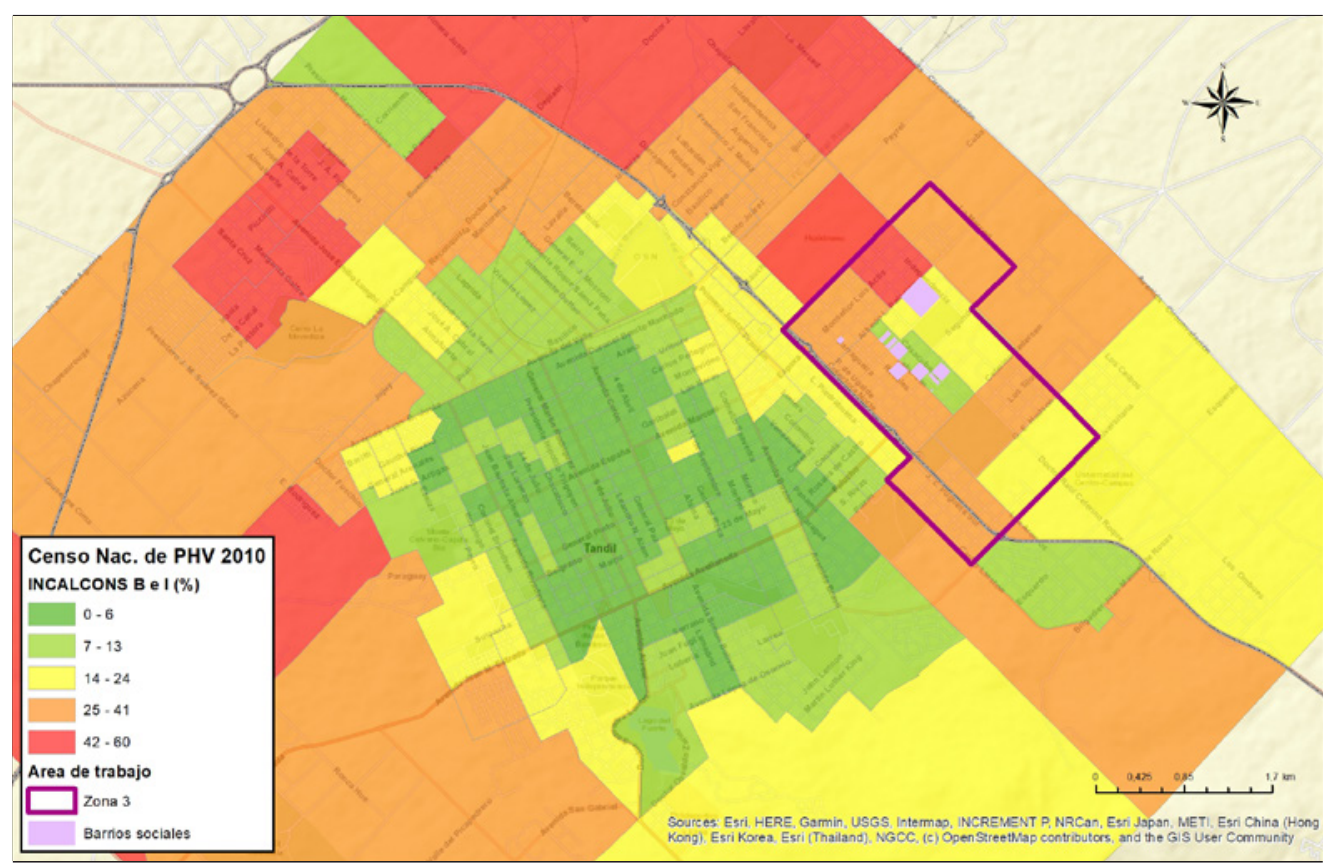

Fuente: elaboración personal sobre la base del Censo Nacional de Población, Hogares y Viviendas. INDEC, 2010.

Como podemos observar, se da prácticamente la misma caracterización que en el mapa anterior. Las peores situaciones se ubican en torno a la ruta y a la avenida de acceso, y se ve incluso un sector con situación aún más compleja al norte del área de trabajo. La mayor superficie posee entre el 25 y el $41 \%$ de las viviendas en las categorías básica e insuficiente y duplica el promedio para la ciudad, que asciende a 13,62 \%. Nuevamente, los barrios sociales marcan la diferencia en los radios censales del centro de nuestro sector de interés, una diferencia que se torna menos significativa que en el mapa anterior incluyendo valores intermedios.

Si bien comprendemos que considerando solo estas cuestiones no se ofrece un panorama exhaustivo de la situación, entendemos que son aspectos que nos llevan a acercarnos 
en el camino de comprender las situaciones que viven quienes habitan y/o trabajan en los barrios donde desarrollamos las actividades de extensión.

\section{Procesos metodológicos. Desafíos y experiencias entre la interdisciplina y la cartografía social}

Como ya comentamos, los datos que podemos construir a partir de metodologías cuantitativas que toman aportes de instancias como el INDEC y otras fuentes secundarias nos parecen fundamentales pero no suficientes cuando pensamos en proyectos de extensión y en metodologías participativas. Generar espacios de intercambio de saberes que permitan obtener un diagnóstico comunitario y así trabajar sobre las problemáticas de los barrios Villa Gaucho, Palermo y Selvetti, de la ciudad de Tandil, fue el objetivo inicial del proyecto de extensión que aquí abordamos. Este, valiéndose de la cartografía social como herramienta, se fue situando y propuso prácticas participativas junto a las organizaciones e instituciones nucleadas en la Mesa Barrial y a otros proyectos de extensión vinculados al Punto de Extensión Territorial (Secretaría de Extensión, UNCPBA).

En este sentido, la cartografía social fue una herramienta que facilitó la construcción de una lectura colectiva sobre el territorio, que abonó procesos colectivos que tenían como horizonte la construcción de "instrumentos importantes para a resistência cultural, o ganho de autonomia e controle sobre o espaço" (Seemann, 2010, p. 134). Esta afirmación conlleva la necesidad de concebirla, más que como un instrumento para conocer la realidad, como un argumento para transformarla, tal como señala Montoya Arango (2007), entendiendo que, junto a otras formas de acción colectiva, puede contribuir a la construcción de una sociedad que involucre los saberes y pensares de sectores relegados, caminando hacia una sociedad que los incluya. Por ello coincidimos con este último autor y su equipo, quienes, en otro trabajo de sistematización y debate en torno a diversas experiencias de cartografía social, afirman que

"los procesos de producción colectiva de conocimiento desde los territorios y con estos pueden constituirse en un insumo político fundamental para la protección de los derechos frente a las múltiples presiones desterritorializadoras, apelando a diferentes formas de representación socioespacial. (Montoya Arango et al., 2014, p. 203)

Del mismo modo, consideramos que la cartografía social se presentó como una oportunidad, pues su particularidad radica en la génesis de su elaboración, y por ello resulta innegable el fuerte componente social y político que posee, cuya relevancia reside en la posibilidad de facilitar instancias en las que la población que construye cotidianamente el territorio a ser mapeado pueda explorar los sistemas de objetos y de acciones que lo configuran, recuperando así su historia y significado. Más que la búsqueda de un producto cartográfico acabado, la preocupación fue focalizar en el desarrollo y la valorización del proceso, que posee igual o mayor distinción que el resultado en sí mismo (Rosso, 2018). Por estas razones creemos, junto con Rocha (2012), que la cartografía social

"é uma metodologia experimental, em cuja essência não está a validação ou areprovação de uma situação, mas sim a possibilidade de fazer visível o não visível, dehabilitar outros possíveis cenários, buscando estruturas de vínculos latentes, em dimensões nem sempre questionadas pelas cartografías". (p. 127) 
Como expresamos en anteriores trabajos (Rosso y Escurra, 2019), entendemos que pensar en prácticas participativas implica la construcción desde abajo de procesos democráticos. Por eso, teniendo en cuenta las dimensiones, los límites y posibilidades identificados junto a otros actores del territorio, la apuesta fue ir hacia la concreción de un diagnóstico participativo que hiciera factibles acciones nacidas de percepciones colectivas del territorio y de la delimitación de problemáticas genuinamente identificadas.

Si retomamos el cómo del surgimiento de la propuesta, es importante compartir que nació de la necesidad de crear un diagnóstico participativo que sirviera como instancia inaugural del Punto de Extensión Territorial, iniciativa de la Secretaría de Extensión de nuestra Universidad, y que recuperara las experiencias de articulación en la Mesa Barrial, lo que potenció el trabajo colectivo, construyéndose un proceso que superó y enriqueció lo inicialmente planteado. Pues, a partir de múltiples iniciativas que se desplegaron fruto del diálogo entre diferentes actores, de disparadores trabajados en el mapeo, del protagonismo de niñes y jóvenes, de la relación con otras iniciativas barriales y proyectos de extensión, los objetivos fueron complejizándose y nuestra participación en un proceso barrial que nos antecede y nos sucede fue situándose. Esto implicó desafíos, en lo referido tanto a incorporarnos en un proceso preexistente, a co-construir prácticas democráticas y de reconocimiento desmitificando el rol de la Universidad y nuestro lugar como extensionistas, como a pensar nuestro quehacer interdisciplinariamente, registrando dinámicas y saberes de otres, pensando procesos, dejándonos enseñar y sorprender, rompiendo ideas preconcebidas.

Así, comprendemos que participar de un equipo y de un trabajo interdisciplinario supone múltiples renuncias, entre ellas a que el saber de la propia disciplina es suficiente para dar cuenta del problema; implica reconocer que el acervo teórico práctico aislado de una única disciplina no basta para dar parte de los problemas con los cuales nos encontramos en nuestras prácticas extensionistas (Stolkiner, 1999). El trabajo insterdisciplinario y, en esta oportunidad, la cartografía social se presentó como la posibilidad de reflexión colectiva en torno al territorio, aportando a la identificación de interrelaciones entre las diversas problemáticas, interpelando la realidad desde una perspectiva integral y ayudando a visualizar posibilidades de transformación de la misma.

Esta dupla -cartografía social y trabajo interdisciplinario- debe ser complejizada a partir de lo que entendemos por diálogo de saberes y participación. Superando la premisa idealizada del diálogo de saberes, para trascender a una co-construcción del proceso y una apropiación genuina de la metodología, de la puesta en marcha y lógicamente de los resultados y nuevas acciones, así como de proyectos que de allí se van desprendiendo. Pues participar implica lograr que las necesidades y exigencias sean contempladas. A veces comprendemos la participación solo como estar; otras lo reducimos a dar la palabra, a poder hablar. Pero si nos quedamos allí, en solo poder hablar, y eso no se escucha, no se comparte, no se conjuga y tensiona, no se transforma en hechos que puedan garantizar derechos, esa voz queda desdibujada y puede ser invisibilizada. Permanecemos en la simple enunciación; y participar es incidir, construir horizontes con los sujetos desde sus saberes y necesidades.

Para ello es necesario reflexionar situadamente sobre nuestras prácticas extensionistas, que se encuentran necesariamente junto a otras prácticas, en un contexto que no es externo, dado, establecido, ni tampoco se concibe como un marco estructural para ellas, sino que se conjugan, dialogan, se contradicen y consensúan en una trama que es producida y reproduci- 
da por prácticas y relaciones sociales entre las que se encuentran las propuestas y acciones concretadas bajo este proyecto de extensión. Por eso se impuso como ineludible reflexionar acerca de qué, para qué, cómo, con quiénes, cuándo, dónde y por qué. Es decir, fue necesario establecer su carácter situado (Fernández Soto, 2004), acompañar los procesos que conocimos y actualizar nuestros proyectos a fin de que puedan concretarse en función de las complejas realidades que viven quienes habitan y trabajan en el barrio.

Con estos desafíos por delante nos fuimos encontrando en diversas instancias para conocer junto con otres: docentes de la escuela secundaria, compañeres de otros proyectos de extensión y referentes de la Mesa Barrial. Instancias en las cuales debatimos y compartimos las decisiones en torno a qué dimensiones trabajaríamos a través de la cartografía social.

En esta etapa se hizo disponible el siguiente cuadro, que es resultado de inquietudes sistematizadas en experiencias anteriores que consideramos importantes tener en cuenta al momento de diseñar una metodología que involucrara elaboración de cartografías sociales. Por esta razón la compartimos, para que pueda ser de utilidad para otros procesos similares y sirva como puntapié inicial para pensar participativamente la metodología, con el compromiso de enriquecerla con las singularidades de la experiencia.

Cuadro 1: Puntos de partida para la creación participativa de un proceso de cartografía social

\begin{tabular}{|c|c|}
\hline Definir & Teniendo en cuenta... \\
\hline Objetivo & $\begin{array}{l}\text { ALCANCE: } \\
\text { - ¿Está orientado a visibilizar alguna problemática concreta? } \\
\text { - ¿Hay una temática específica de interés que lo delimite? } \\
\text { FUNCIÓN: } \\
\text { - ¿Pretende solo servir de reflexión entre quienes participan o busca recabar información } \\
\text { que luego pueda ser comunicable? } \\
\text { ESCALA: } \\
\text { - ¿Qué límites definen el territorio a mapear? }\end{array}$ \\
\hline $\begin{array}{l}\text { Preguntas } \\
\text { orientadoras }\end{array}$ & $\begin{array}{l}\text { - Resultado que se pretende alcanzar. } \\
\text { - Compatibilidad entre paralelos o sucesivos mapeos que recuperen la misma información. }\end{array}$ \\
\hline $\begin{array}{l}\text { Metodología } \\
\text { de mapeo }\end{array}$ & $\begin{array}{l}\text { TIEMPO disponible: } \\
\text { - ¿Hay posibilidad de hacer reiterados talleres? ¿Con las mismas personas? } \\
\text { - ¿En qué contexto se realiza? ¿Es la única actividad de la jornada? } \\
\text { PARTICIPANTES: } \\
\text { - Edades y características. } \\
\text { ESPACIO físico: } \\
\text { - Características y mobiliario disponible. }\end{array}$ \\
\hline $\begin{array}{l}\text { Recursos } \\
\text { necesarios }\end{array}$ & $\begin{array}{l}\text { - Mapa base (escala y nivel de detalle). } \\
\text { - Iconos/simbología/colores (grado de estructuración del mapeo). }\end{array}$ \\
\hline
\end{tabular}

Fuente: elaboración propia, 2020.

Tal como se indica en el cuadro, es preciso definir, en primer lugar, el objetivo general de la propuesta, teniendo en cuenta el alcance, la función y la escala que puedan luego expresarse en una o varias preguntas orientadoras que servirán de norte para el desarrollo del o de los mapeos. Seguidamente, se deberá consensuar concretamente la metodología de mapeo que permitirá responder aquella/s pregunta/s definida/s, para lo cual servirá de insumo considerar el tiempo disponible, las particularidades de les participantes y el espacio físico 
con el que se contará para su desarrollo. Por último, entonces, se estará en condiciones de listar los recursos necesarios para garantizar el proceso. Un factor común a todas estas decisiones, claro está, es la participación de la comunidad con la que se está trabajando, ya sea por medio de las instituciones $\mathrm{y} / \mathrm{u}$ organizaciones barriales, referentes, delegados, o quienes se defina, puesto que es preciso delinear la forma en la que esa participación se va a operacionalizar, que esta se garantice en cada momento, y porque es imposible que todas las personas involucradas participen de todos los procesos al mismo tiempo.

En cuanto a nuestra experiencia junto a la Mesa Barrial de Villa Gaucho, Palermo y Selvetti, surgieron en esta instancia tres grandes inquietudes que organizamos en torno a consignas que guiarían los mapeos colectivos: una relacionada con las problemáticas que la comunidad identifica; otra atinente a los espacios que son valorados y se disfrutan en el barrio, y una última vinculada con la dimensión del deseo, del territorio deseado en tanto posibilidad de imaginar aquello que anhelamos que esté y hoy no existe en nuestro barrio (Escurra y Rosso, 2019). Si bien en un principio la intención de contar con un diagnóstico participativo sobre la situación actual de los barrios Villa Gaucho, Palermo y Selvetti nos remitió siempre a identificar aquello que "no estaba bien" o que "nos gustaría que fuera de otro modo", surgió como importante poder relevar también aspectos positivos y potenciadores de vivir allí, elementos que hacen al disfrute de determinada apropiación del territorio y evidencian el sentido de pertenencia e identidad. De este modo, se coincidió en la importancia de dar valor a lo que hace bien, gusta y se disfruta del espacio cotidiano, a fin de poder reconocer eso que genera unión, encuentro y alegrías, y puede potenciar lazos, intereses, iniciativas comunitarias y demandas comunes.

Así, se fue trabajando en los elementos de la metodología para garantizar la recuperación de estas tres dimensiones definidas, por lo que nos propusimos elaborar colectivamente tres mapas. Sus objetivos, las preguntas orientadoras de cada mapeo, la dinámica de la actividad y los recursos fueron diseñados y sintetizados en conjunto con quienes conformaban la Mesa Barrial, referentes de organizaciones e instituciones del barrio.

Se realizaron talleres con mesas rotativas de mapeo y también mesas de mapeos al paso, utilizando como base las propuestas metodológicas de Risler y Ares (2013), en el marco de actividades cotidianas o previamente programadas de las instituciones y organizaciones del barrio. Se logró la construcción de 33 mapas que reflejaron aspectos de las tres dimensiones propuestas, con la participación principal de adolescentes y mujeres que viven, trabajan y/o transitan instituciones educativas públicas de los barrios Villa Gaucho, Palermo y Selvetti de Tandil. A la vez, en articulación con el Proyecto de Extensión "Hábitat y Derecho a la Ciudad" (FCH/Secretaría de Extensión, UNCPBA), se efectuaron recorridas barriales, encuestas (definidas también en el marco de la Mesa Barrial) y un registro escrito y fotográfico sobre la base de las dimensiones propuestas en los talleres de mapeo. Tales actividades fueron posibles junto a docentes, referentes, niñes y jóvenes de las instituciones educativas formales y no formales que trabajaron en las aulas y espacios a partir de los diferentes insumos que se construyeron en el proceso.

De esta manera, el proyecto se fue entramando en las dinámicas institucionales y barriales, dando lugar a múltiples actividades y propuestas que giraron en torno a debatir y repensar el territorio que cotidianamente se habita y construye, sus problemas, sus aspectos valiosos y los deseos que suscita, lo cual implicó una retroalimentación de los procesos que, para- 
lelamente y en interacción, surgieron en los diferentes espacios barriales. Hacia fin de año (noviembre de 2018), desde la Mesa Barrial se definió concretar una actividad que pretendió reunir a todas estas experiencias en un Festival que se denominó "Así vive la Barriada Villa Gaucho, Palermo, Selvetti", en el que se compartió y disfrutó mucho de lo trabajado y aprendido colectivamente. Retomando reflexiones de otro trabajo, volvemos a expresar que:

"[c]como habíamos planteado la construcción de un diagnóstico participativo, concibiéndolo no desde una mirada etapista ni como una intervención aislada del territorio, reconocemos también que no estamos frente a una tarea cumplida; al contrario. Pero sí podemos observar cómo el trabajo emprendido a través de la cartografía social en el marco de un proceso promovido junto a otres ha abonado procesos ya existentes y fomentado otros que nos trascienden y desbordan". (Rosso y Escurra, 2019, p. 17)

\section{La sistematización. Los mapas como producto y proceso}

Coincidimos con lo que Torres Carrillo (2019) postula respecto de la sistematización como reconstrucción de los sentidos de la práctica. El proceso extensionista parte de una producción intencionada de conocimientos que, entendida desde una modalidad participativa de investigación, reconoce la complejidad de las prácticas de acción social al tiempo que reconstruye las prácticas desde la experiencia de sus protagonistas, interpreta críticamente la práctica transformadora, fortalece el potencial emancipador de la práctica y aporta a la conceptualización de la transformación social, o sea, al pensamiento crítico.

Somos conscientes de que no existe una linealidad entre lo que se mapea y un sentido transformador emancipador; sin embargo, reconocemos que las instancias y los procesos participativos que han llevado a la construcción de mapas del barrio posibilitaron involucrarse, intercambiar y dar visibilidad a los problemas comunes y a las conquistas necesarias de ser defendidas. Análisis, percepciones y debates en cuanto a lo que ha sido el proceso de elaboración de los mapas ya han sido presentados en otro trabajo (Rosso y Escurra, 2019); la intención es compartir aquí los resultados y la particularidad de haber sistematizado por medio de una plataforma de Web Mapping todo lo mapeado en dos de las dimensiones trabajadas: la de identificación de problemáticas y la de reconocimiento de espacios valiosos y de disfrute.

Coherentes con los principios del equipo, decidimos asimismo colectivizar la sistematización y crear un único mapa de cada dimensión -para posibilitar la creación posterior de varios temáticos- que sintetizara los aportes de todas las personas participantes y permitiera transformar esa multiplicidad de mapas originalmente creados en los talleres de cartografía social en información compartible y fácilmente legible. Las Tecnologías de la Información Geográficas son una herramienta central para auxiliar en el proceso de georreferenciación de los datos e información contenida en los mapas colectivos y de asociación de variables espaciales que ayuden a su comprensión en contexto y futura resolución, así como la elaboración de cartografías que admitan una fácil lectura de los resultados y sean de utilidad para acompañar acciones de la comunidad en general.

Específicamente, definimos adoptar las herramientas de Web Mapping, ya que permiten incorporar algunas de las potencialidades de los Sistemas de Información Geográfica (SIG) a plataformas web utilizando un navegador como aplicación principal sin la necesidad de 
instalar softwares especializados de escritorio, lo cual facilita un mayor acceso y posibilidades de trabajo con información geográfica digital. De este modo, dotar a un navegador web de capacidades de visualización y edición de geodatos hace que este llegue a un público distinto y abre nuevas oportunidades de apropiación. Múltiples son las cualidades que se presentan en estas plataformas, como la particularidad de exigir para su uso un perfil menos técnico, lo cual potencia la posibilidad del trabajo colaborativo, personalizar aplicaciones y combinar la cartografía con otros elementos, como los disponibles en la web (Olaya, 2014). Siguiendo la definición ofrecida por López Trigal (2015), existen principalmente tres ventajas de la cartografía web frente a la cartografía tradicional en papel. Estas son:

"el aumento de la audiencia que puede acceder a la cartografía; las posibilidades de interacción que ofrece al usuario, que puede cambiar la escala de visualización, desplazarse a otra zona, susperponer capas, consultar información de un punto o de un objeto y otras operaciones, y al haber desaparecido las limitaciones del papel, la enorme cantidad de información que puede ir asociada a un mapa en forma de tablas, diagramas, textos y multimedia". (p. 83)

En el marco de nuestro proyecto se definió utilizar la plataforma uMap —-perteneciente al Proyecto OpenStreetMaps-, la cual permite de forma muy intuitiva cargar información geográfica, asociarle atributos que se desplegarán al hacer clic sobre la entidad y definir las formas de visualización, pudiendo incluso recuperar los íconos utilizados en los mapas en papel, precisar su color y tamaño, y definir el mapa base. Se trata de cartografía web que muestra datos geográficos, en este caso vectoriales, organizados en teselas o capas de información del mismo modo que en un SIG.

Para concretizar esta desafiante sistematización, se diseñó y puso en marcha un Taller de Mapeo colaborativo y Web Mapping, que se desarrolló en dos jornadas en el Aula de Informática de la Facultad de Ciencias Humanas, UNCPBA. La intención fue convocar al espacio universitario a les estudiantes del nivel secundario que formaron parte del proceso de mapeo y a otras personas interesadas en conocer la metodología desarrollada, aprender algunas potencialidades de las plataformas de mapeo online y al mismo tiempo colaborar en la digitalización de los 33 mapas obtenidos en papel en los talleres de cartografía social antes realizados. Alí se procedió a la digitalización colaborativa de puntos, líneas y polígonos en la plataforma uMap, creando una capa de información espacial por cada uno de los mapas en papel, lo cual hizo factible obtener dos visualizadores que pueden consultarse y explorarse libremente.

Gracias a las herramientas de visualización de datos espaciales que ofrece la plataforma, es posible navegar a diferentes escalas y explorar las marcas mapeadas, ya que al posicionar el cursor sobre ellas se despliega la información asociada. Al mismo tiempo, se pueden realizar consultas por mapa desde el panel que se despliega a la izquierda, como, por ejemplo, dejar solo visible el mapa elaborado por 4to. año B de la EES № 14, o combinar varios mapas y ver juntos todos los construidos en la EES $N^{\circ} 14$. La plataforma permite también realizar búsquedas por variable, lo cual habilita, por ejemplo, ver todas las marcas que se mapearon respecto de la problemática de inundaciones, calles intransitables, falta de semáforos o falta de iluminación, etc., y la forma de acceder a ello es haciendo clic en el mismo panel de la izquierda donde se indica "Navegar los datos" y escribir en la ventana emergente la variable a visualizar. 
Figura 3: Visualizador de los datos sistematizados en la plataforma uMap en torno a las problemáticas mapeadas en Villa Gaucho, Palermo y Selvetti

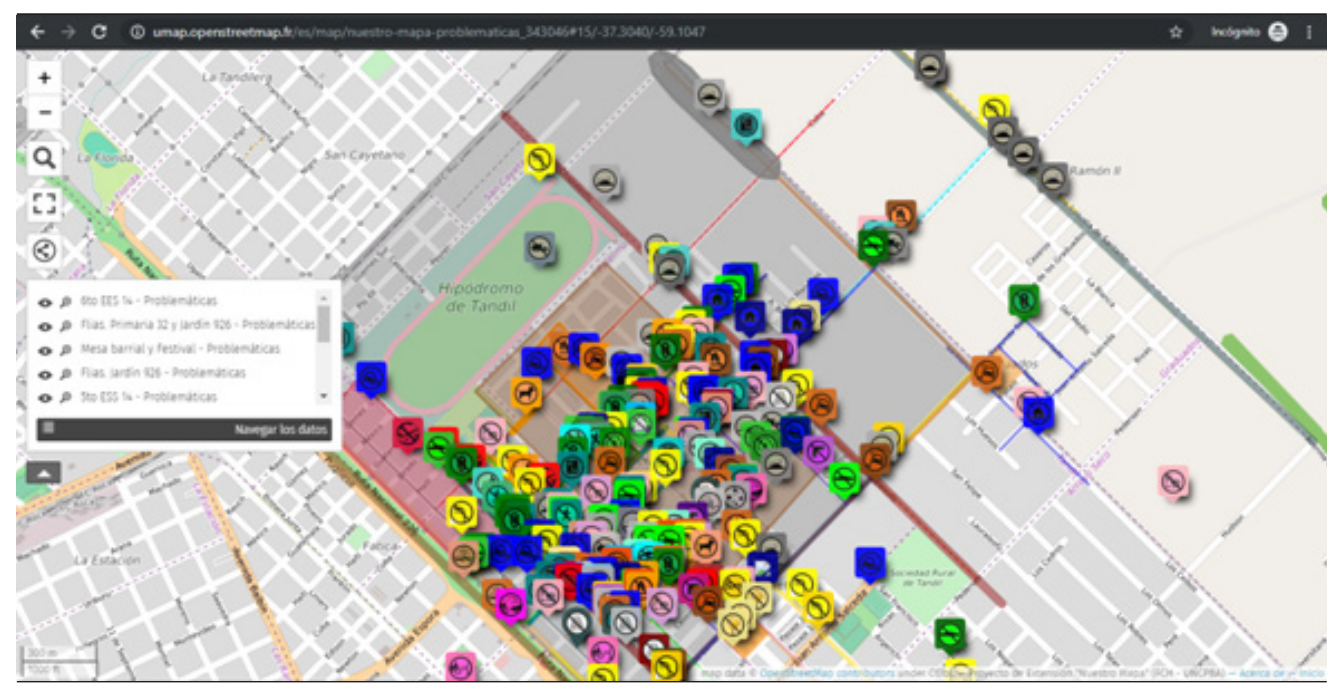

Fuente: Proyecto de Extensión "Nuestro Mapa”, 2019.

https://umap.openstreetmap.fr/es/map/nuestro-mapa-problematicas_343046\#16/-37.3080/-59.1043

Tal como puede evidenciarse en la plataforma de sistematización, aparece enunciada una multiplicidad y concentración importante de puntos vinculados a problemas comunes, varios de ellos en estrecha relación con la infraestructura urbana y el derecho a la vivienda y a la ciudad, tales como la identificación de calles inundables, intransitables y baches, las zonas inundables, la falta de alcantarillas, de asfalto, de garitas para esperar el colectivo, de veredas y de cordón cuneta, calles sin abrir y pozos abiertos. Así también fueron señalados con déficit los servicios de iluminación en la vía pública, el tendido y la conexión domiciliaria de cloacas, la red de agua potable y el acceso a gas natural. La falta de viviendas dignas fue mencionada como un problema, al tiempo que se refirieron al transporte público como deficitario en los recorridos y en la insuficiencia de puntos de recarga de tarjeta - SUMO-. La ausencia de cajero automático y de farmacias fue señalada como dificultad y se evidenciaron también problemas en torno a la localización de basurales clandestinos en diferentes puntos sumados a la falta de recolección de residuos.

Por otra parte, se identificaron marcas con referencia al tránsito y a la circulación: falta de semáforos, de reductores de velocidad y de señalética, calles doble mano, accidentes de tránsito, ruidos de motos y autos, alta velocidad y perros sueltos. En cuanto a los espacios públicos abiertos (parques y plazas), se señaló: falta de árboles, de canillas y de juegos de plaza. También la inexistencia de Internet libre. La cuestión presupuestaria se marcó en las instituciones públicas presentes en el barrio (escuelas, centros de salud y comunitarios), como también se identificaron en los mapas situaciones conflictivas como peleas y pugnas entre jóvenes, consumos problemáticos, y situaciones de maltrato policial a jóvenes.

A continuación presentamos dos mapas a modo de ejemplo que fueron elaborados con SIG a partir de la información digitalizada en las plataformas web. Con los mismos se pretende disponibilizar salidas cartográficas a partir de mapas de densidad que sintetizan la distribución de las marcas agrupadas por temática o variable, en donde la intensidad del 
color representa la cantidad de veces que fue mapeada la problemática en ese lugar. Bajo este procedimiento fueron elaborados 16 mapas temáticos facilitados a la Mesa Barrial para que puedan estar a disposición para futuros análisis o intervenciones.

Figura 4: Mapas de densidad de marcas identificadas por variable (problemáticas) a partir de sistematización de los talleres de cartografía social del Proyecto Nuestro Mapa

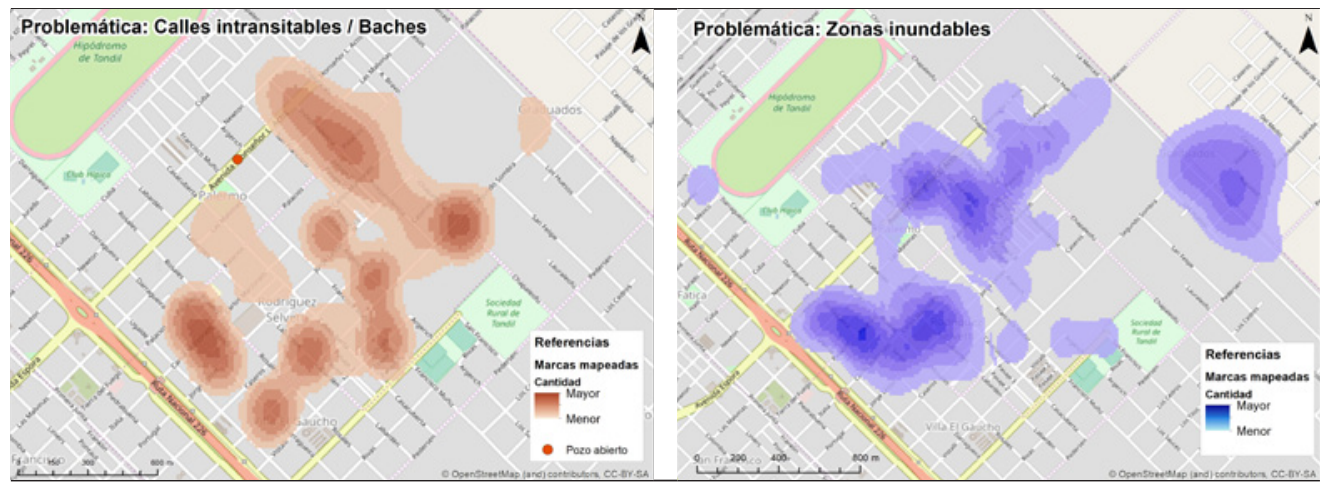

Fuente: elaboración propia a partir de resultados del Proyecto de Extensión "Nuestro Mapa", 2019.

Vivir el barrio implica, además de las problemáticas que se comparten y sufren, reconocer aquello que se valora y disfruta. Es por ello que se generó del mismo modo un visualizador de los datos con relación a la identificación de lugares que se disfrutan en el barrio e instituciones $u$ organizaciones que se consideran valiosas.

\section{Figura 5: Visualizador de los datos sistematizados en la plataforma uMap, en torno a lugares} valiosos y de disfrute en Villa Gaucho, Palermo y Selvetti

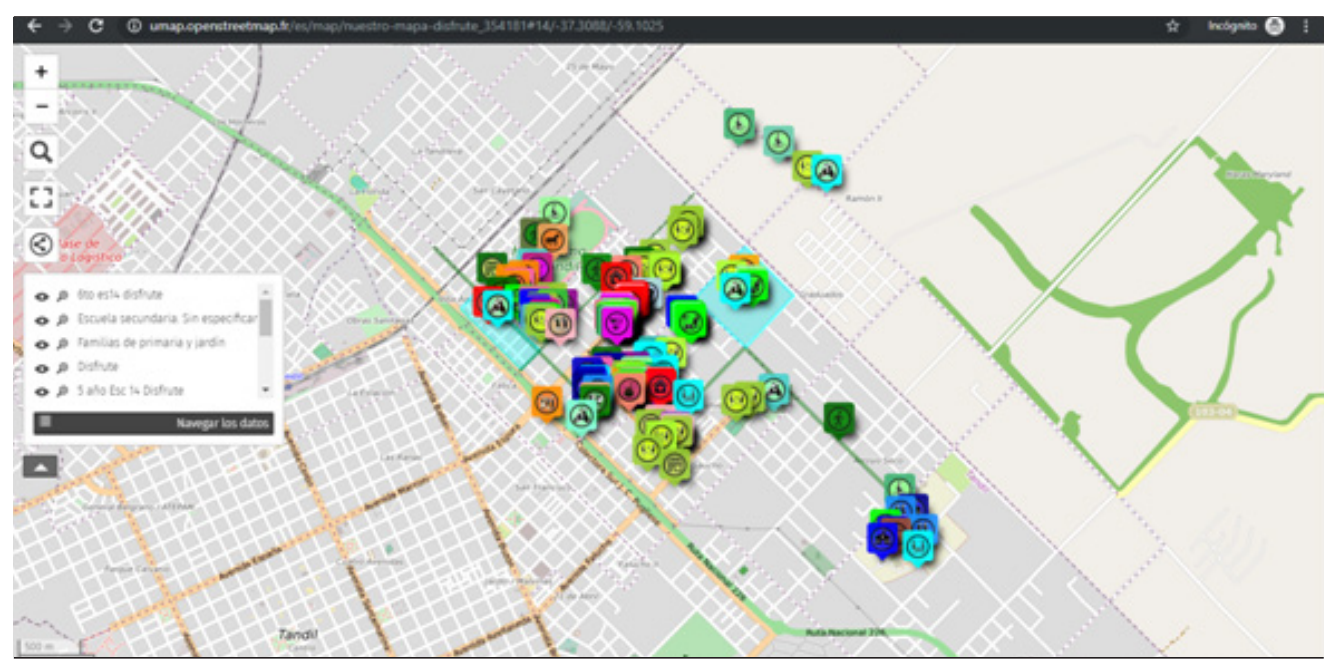

Fuente: Proyecto de Extensión "Nuestro Mapa", 2019

https://umap.openstreetmap.fr/es/map/nuestro-mapa-disfrute_354181\#17/-37.31021/-59.10609

Al observar los mapas en los que se trabajó con la consigna: ¿Qué espacios, cosas, acciones nos parecen valiosos y disfrutamos de nuestro barrio?, podemos visualizar la impor- 
tancia dada por las personas que participaron a las organizaciones e instituciones estatales y de la sociedad civil presentes en el territorio. Las escuelas y jardines, los centros de salud, la biblioteca, el centro de día y las organizaciones culturales barriales fueron referenciados con diferentes marcas que valoran y reconocen estos espacios barriales, ya sea por las actividades que se ofrecen, como talleres artísticos, de cocina, huerta, espacios de educación y lectura, comedores o cocinas comunitarias, o por ser indicados como espacios de recreación, referencia, organización y ayuda en múltiples situaciones. También fueron mapeados los diferentes espacios donde aparecen actividades al aire libre, como caminar, andar en bici o a caballo, tomar mate, jugar al fútbol u otro deporte, etc. Se trata de espacios públicos o privados pero a los que se accede y disfruta en el barrio, como las plazas y espacios recreativos abiertos, la pileta del Club Hípico e incluso aparecen algunos comercios asociados a actividades de ocio, distensión y encuentro con amigos y amigas. La mayor cantidad de marcas aparece en la Plaza de Palermo, el predio Limache, la pileta antes mencionada y la plaza lindante al Jardín № 926.

Los siguientes mapas de densidad construidos de igual modo que con las problemáticas muestran, por un lado, las instituciones que funcionan como espacios de referencia en Villa Gaucho, Palermo y Selvetti y, por el otro, los lugares que se valoran como espacios de esparcimiento.

Figura 6: Mapas de densidad de marcas identificadas por variable (disfrute y valioso) a partir de sistematización de los talleres de cartografía social del Proyecto Nuestro Mapa

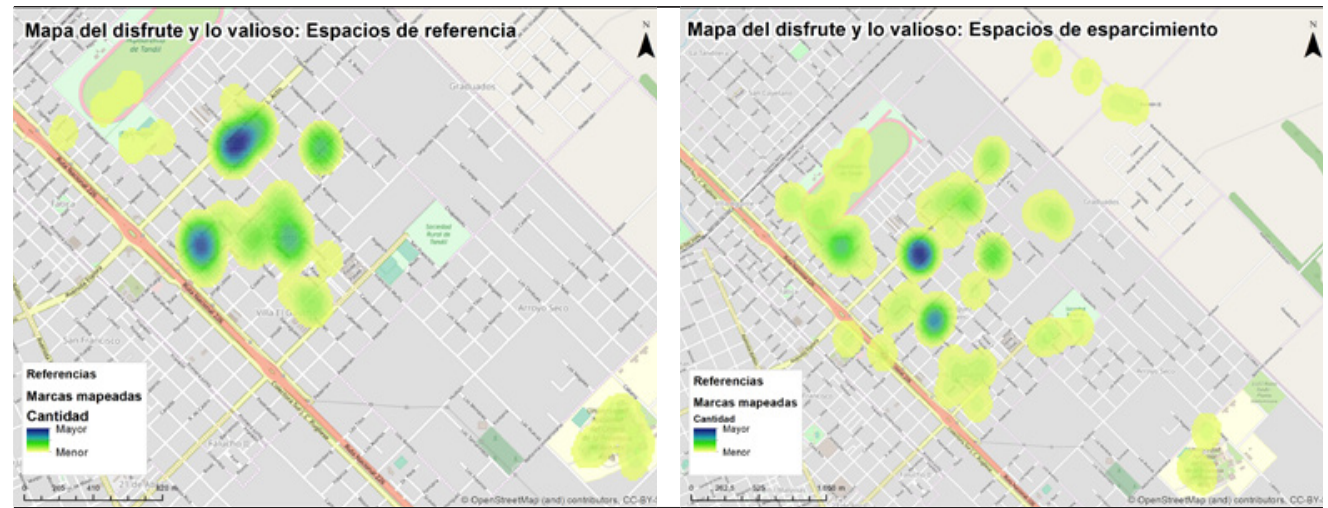

Fuente: elaboración propia a partir de resultados del Proyecto de Extensión "Nuestro Mapa", 2019.

La tercera dimensión abordada en cada taller de mapeo y/o mesa de mapeo se trabajó por medio de la elaboración de un Mapa del Deseo con la consigna: ¿Cómo quisiéramos que fuera nuestro barrio? ¿Qué tendría que haber? ¿Dónde? Si bien podemos ver que en los otros mapas también aparece fuertemente la dimensión del deseo vinculada a los problemas que vemos y los espacios que disfrutamos, en este nos propusimos pensarla, compartirla y mapearla, dejándonos soñar en torno al territorio deseado. Lógicamente, resultó imposible digitalizar en espacialidades exactas y expresar de forma sintética la riqueza de lo que enuncian, afirmación que explica la inexistencia de una sistematización con Web Mapping, pero es importante evidenciar que dan cuenta de la necesidad de pensar respecto de las desigualdades en la ciudad. 
Lo mapeado no simplemente responde a una problemática concreta, sino que habilita la posibilidad de pronunciar cómo sería el barrio deseado cuanto a los espacios de recreación, la infraestructura urbana, el mejoramiento de las organizaciones presentes (escuela, centro de salud, biblioteca, etc.), la presencia y acompañamiento profesional, la disponibilidad de comercios y servicios de esparcimiento, y hasta las relaciones y vínculos entre quienes transitan y construyen el barrio cotidianamente. Los mapas construidos dan cuenta de elementos comunes que componen los deseos y las necesidades de quienes viven y transitan el barrio, algunos de los cuales hacen al consumo pero otros tantos se relacionan estrechamente con derechos. $Y$ en este sentido consideramos valiosa esta manifestación, puesto que refleja lo que se desea, cómo sería ese territorio, ese barrio en el que gustaría vivir y también de las coincidencias que hay con referencia a qué se quiere y necesita, lo que hace posible graficar, dibujar de qué hablamos cuando hablamos de derecho a la ciudad. El acceso a la salud, al ocio, a los servicios esenciales está presente, igual que el fortalecimiento de lazos comunitarios existentes que hacen a la identidad y la sociabilidad en el barrio y la ciudad. En esta línea:

"La cuestión de qué tipo de ciudad queremos no puede estar divorciada de la que plantea qué tipo de lazos sociales, de relaciones con la naturaleza, de estilos de vida, de tecnologías y de valores estéticos deseamos. El derecho a la ciudad es mucho más que la libertad individual de acceder a los recursos urbanos: se trata del derecho a cambiarnos a nosotros mismos cambiando la ciudad". (Harvey, 2008, p. 23, en Valente Ezcurra, 2018, p. 5)

Conscientes de que este relato es incompleto y no llega a destacar lo rico del proceso transitado y la densidad de cada uno de los mapas que se construyeron, se sintetiza groseramente lo construido y se propone compartirlo, buscando lugar para seguir profundizando en cómo construimos metodologías participativas y situadas. Revalorizamos el derecho y el deseo de pronunciar las palabras, de pronunciar el mundo, de imaginar la sociedad que deseamos.

\section{Reflexiones finales}

Tal como hemos debatido, los procesos de precarización en el trabajo determinan la precarización de la vida en su conjunto para una importante parte de la población. La precariedad como característica de la política de Estado en escenarios neoliberales ha impactado profundamente en los territorios y en la vida cotidiana de los sujetos que los usan y transitan, coartando posibilidades para la protección de la vida. Sin embargo, estas situaciones de precariedad también habilitan un posible germen que potencie el pensar y el hacer desde otras lógicas de protección que pueden ser transformadoras de las condiciones existentes. Es en esa posibilidad en la que nos posicionamos como equipo de extensión y nos ponemos a disposición de trayectos y experiencias preexistentes en territorio para pensar conjuntamente, desde el momento cero, cuáles pueden ser los aportes que a partir del conocimiento disciplinar y académico podemos hacer disponibles, no para que el fin sea brindar herramientas/conocimientos/saberes, sino para que, con ese poner a disposición lo que tenemos, nos permitamos construir junto a otres instancias y productos superadores.

No debe dejar de interpelarnos el lugar que en la práctica extensionista tiene cada uno de los sujetos. La inercia con la que se conciben dicotomías como universidad-comunidad, 
saber académico-saber popular, teoría-práctica, sujeto-objeto, no hace más que fortalecer estereotipos y profundizar la fragmentación. Aunque es importante reconocer especificidades, disponer herramientas, saberes, trayectorias y recorridos, nada de ello debe alejarnos del potencial transformador que el respeto y la valoración por lo otro tienen, fundamentalmente cuando los contextos materiales y simbólicos nos han forzado a construir territorialidades disímiles. Tampoco pueden movernos conceptualizaciones idealizadas sobre los barrios, las situaciones de precariedad, los lazos y relaciones en contextos de vulneración de múltiples derechos. Los conflictos y las violencias son parte de la sociedad en que vivimos y trabajamos. Romantizar sectores que, incluso, sufren avasallamientos sistemáticos, resulta perverso.

Del mismo modo, concebir a la universidad separada (o por encima) de la comunidad ubica un otres diferente de un nosotres. Lógicamente que la diferencia y/o la especificidad de la formación y de nuestro sostén laboral nos definen en algún punto, pero, ¿en qué sentido pensar esa diferencia y esa especificidad, abonando a qué procesos, reconociendo qué saberes? ¿Podemos pensar la universidad sin la comunidad? ¿De dónde venimos nosotres? ¿Quiénes somos? ¿Qué nos mueve? ¿Qué nos preocupa? ¿Qué nos interpela? ¿Por qué nos interpela? ¿Qué nos enseña? ¿Qué compartimos y para qué? ¿Qué podemos co-construir a través de procesos de extensión universitaria?

Estos desafíos ético-políticos y estas preguntas que fuimos co-construyendo agregaron al proceso un ingrediente: reconocer que en momentos donde la urgencia es tan fuerte para las personas que trabajan en instancias públicas de protección social es difícil —pero no imposible-, detenerse y mirar, problematizar y problematizarse en las propias prácticas, habilitar la pregunta en instancias colectivas, combinar la resistencia con la propuesta. Con seguridad, esto podíamos aportar pero no en soledad. Aportar no es igual a transferir sino que lo pensamos como co-construir junto a otres tan diferentes y tan similares.

Y fue así como propusimos corrernos de una mirada romántica acerca de jóvenes, mujeres, trabajadores, el barrio y la extensión, pero también de una mirada fatalista, de resignación. Reflexionando en cuanto al desafío que implica utilizar herramientas metodológicas participativas y proponiendo superar las dicotomías sujeto-objeto, investigador-investigado para convidarnos a un proceso que nos trascendió como extensionistas pero del cual formamos parte, aportamos y aprendimos. Fuimos desarrollando prácticas en el sentido de acercarnos a ese objetivo que se fue construyendo, a esa mirada colectiva y compleja sobre el territorio, su entramado social, sus problemas, sus potencialidades y las posibilidades de transformación. La construcción de un proceso de diagnóstico participativo, concibiéndolo no desde una mirada etapista ni como una intervención aislada del territorio, nos impuso reconocer que no estamos frente a una tarea cumplida, al contrario.

En este marco, reiteramos que visualizamos la cartografía social como una herramienta y como un argumento para transformar la realidad y movilizar formas de pensar colectivamente. A este planteo inicial sumamos la posibilidad de construir saberes y poderes sociales que disputen y problematicen las situaciones vividas y cómo sería el territorio deseado por quienes lo transitan. Propusimos en este proceso abrir puertas para reconocer lo que se identifica y se valora del lugar donde se vive, como también posibilitar al trabajo compartido, abonando a procesos que rompan con el aislamiento y el sufrimiento individual.

Y con respecto a esto último, nos parece importante destacar las dimensiones del deseo y del disfrute trabajadas, porque aparecen muchas veces limitadas, cercenadas para ciertas 
personas según su sexo, su raza y su condición social. Asociados a la idea de merecimiento o de estatus, el deseo y el disfrute son coartados para múltiples sujetos, que quedan atrapados en relaciones tutelares que apagan y/o invisibilizan voces.

Poder desear y disfrutar de una ciudad, de un territorio, de un futuro. Poder pensar y decir más allá de la inmediatez que supone resolver la vida cotidiana. Poder construir decires y pensamientos en torno a qué tipo de relaciones, de organizaciones, de barrio y de ciudad queremos. Y que ese pensar pueda ser también un decir junto a otres y que no esté divorciado de los anhelos que tenemos, de los lazos sociales que construimos ni de qué tipo de relaciones con la naturaleza y con la sociedad deseamos.

Estos fueron los desafíos que fuimos cocreando junto a una Mesa Barrial con años de trayectoria, con momentos de trabajo intensos que permitieron alcanzar reivindicaciones que hoy se recuerdan con alegría y orgullo. Allí, nuestro desafío siempre fue, y continúa siendo, sumarnos a una amalgama de recorridos disímiles y diversos en pos de potenciar lo existente, sin avasallar, respetando, reconociendo, poniendo en valor y, sobre todo, aprendiendo de lo que cada organización e institución que compone la Mesa viene desarrollando en territorio.

Podemos observar cómo el trabajo emprendido a través de la cartografía social en el marco de un proceso promovido junto a otres ha abonado procesos ya existentes y fomentado otros que nos trascienden y desbordan. Ha sido central la participación de múltiples sujetos (niñes, estudiantes, docentes, referentes de organizaciones de la sociedad civil y de instituciones barriales, mujeres madres, docentes, extensionistas) que intervinieron colectivamente para visibilizar problemas y reconocer espacios valiosos para quienes habitan el barrio, como, por ejemplo, el Festival "Así Vive la Barriada" en diciembre de 2018, la jornada de presentación de resultados a la comunidad y a funcionarios públicos en septiembre de 2019, y el acompañamiento para con los reclamos por el espacio Limache en febrero y marzo de 2020 (Mesa Barrial, 2020).

Repensar estas cuestiones a la luz de las herramientas y posicionamientos que hemos ido construyendo junto al trabajo en territorio, a la vez que potenciar y acompañar a actores que se hacen preguntas y buscan construir estrategias colectivas, como las Mesas Barriales, puede ser un gran desafío en el marco de nuestras prácticas extensionistas.

\section{Referencias bibliográficas}

Antunes, R. (2009). El trabajo entre la perennidad y la superfluidad. Algunos equívocos sobre la deconstrucción del trabajo. En Fernández Soto, S. y Tripiana, J. (Orgs.). Políticas sociales, trabajo y trabajadores en el capitalismo actual. Aportes teóricos y empíricos para una estrategia de emancipación. Espacio Editorial.

Barrera, A. (2013). Estado y pobreza. La mediación de las organizaciones de la sociedad civil. Kairos, 17(32). Universidad Nacional de San Luis. http://www.revistakairos.org/wp-content/uploads/k39-completa.pdf Fernández Soto, S. (2004). Implicancias de la cuestión social en la intervención profesional. Escenarios, (8), 98-111. UNLP/Espacio Editorial.

Fernández Soto, S. y Tripiana, J. (2009). Políticas sociales, trabajo y trabajadores en el capitalismo actual. En Fernández Soto, S. y Tripiana, J. (Orgs.). Políticas sociales, trabajo y trabajadores en el capitalismo actual. Aportes teóricos y empíricos para una estrategia de emancipación. Espacio Editorial.

Fernández Soto, S.; Tripiana, J; Vacca, M. L.; Escurra, M. y de Ávila, V. (2011). Asistencia social a nivel municipal. Prácticas, sentidos y espacios profesionales en la década del 2000. Revista de Trabajo So- 
cial Plaza Pública. Carrera de Trabajo Social, FCH, UNCPBA. https://revistaplazapublica.files.wordpress. com/2014/06/6-31.pdf

Fernández Soto, S.; Tripiana, J.; Vacca, M. L.; Escurra, M., Piñeyro, V. y de Ávila, V. (2012). La materialización del proceso de gestión de la política de asistencia social a nivel municipal desde el trabajo y los trabajadores. La experiencia de Tandil en la década del 2000. En Encuentro Estado, Políticas Sociales y Sociedad. Debates latinoamericanos. PROIEPS, FCH, UNCPBA.

Fernández Soto, S.; Tripiana J.; Vacca, M. L; Leivas, M.; Escurra, M., De Ávila, V. (2015). Políticas sociales, territorio y conformación de espacios sociales. La trama de la asistencia en el ámbito local, Tandil 2003-2010. Revista de Trabajo Social Plaza Pública, 85-95. Carrera de Trabajo Social, FCH, UNCPBA. https://revistaplazapublica.files.wordpress.com/2016/03/ne10.pdf

Fleury, S. (1997). Estado sin ciudadanos. Lugar Editorial.

Fleury S. y Molina C. (2000). Modelos de protección social. INDES.

Harvey, D. (2008). El derecho a la ciudad. New Left Review, (53). Londres.

(2013). Ciudades Rebeldes. Del derecho a la ciudad a la revolución urbana. Ediciones Akal.

INDEC (2012). Censo Nacional de Población, Hogares y Viviendas 2010. Resultados definitivos, Serie B No 2. Tomo 1. Argentina.

(2013). Censo Nacional de Población, Hogares y Viviendas 2010. Base de datos REDATAM, Definiciones de la base de datos. Argentina.

Linares, S. (2008). Territorio y exclusión social en la ciudad de Tandil: la acción del Estado y de las organizaciones de la sociedad civil. En Lan, D. y Velázquez, G. (Eds.). Contribuciones geográficas para el estudio de la ciudad de Tandil. CIG, FCH, UNCPBA. REUN.

(2011). Análisis y modelización de la segregación socioespacial en ciudades medias bonaerenses mediante Sistemas de Información Geográfica: Olavarría, Pergamino y Tandil (1991-2001). Tesis de doctorado en Geografía. Universidad Nacional del Sur.

López Trigal, L. (Dir.) (2015). Diccionario de geografía aplicada y profesional: terminología de análisis, planificación y gestión del territorio. Universidad de León.

Mesa Barrial (2020). Proyecto de Extensión Derecho a la Ciudad. Informe técnico inédito. FCH, UNCPBA. http://www.fch.unicen.edu.ar/wp-content/uploads/2020/02/Informe-T\%C3\%A9cnico-Limache.pdf

Merklen, D. (2005). Pobres ciudadanos. Las clases populares en la era democrática (Argentina, 1983-2003). Gorla.

Migueltorena, A. y Linares, S. (2019). Mercado del suelo urbano y producción del espacio residencial en la ciudad de Tandil, Argentina. Cuadernos de Vivienda y Urbanismo, 12(23) https://revistas.javeriana.edu.co/ files-articulos/CVU/12-23\%20(2019-I)/151558490002/

Montoya Arango, V. (2007). El mapa de lo invisible. Silencios y gramática del poder en la cartografía. Universitas Humanística, (063), 155-179. Pontificia Universidad Javeriana. Bogotá.

Montoya Arango, V.; García Sánchez, A. y Ospina Mesa, C. A. (2014). Andar dibujando y dibujar andando: cartografía social y producción colectiva de conocimientos. Nómadas, (40), 190-205. Universidad Central Bogotá. http://www.redalyc.org/articulo.oa?id=105131005013

Municipalidad de Tandil (2004). Tandil frente a los nuevos escenarios sociales. Propuesta de Descentralización y Zonificación Municipal. Secretaría de Desarrollo Social.

Netto, J. P. (1992). Capitalismo Monopolista y Servicio Social. Cortez Edit.

Olaya, V. (2014). Sistemas de Información Geográfica. Creative Common Atribución.

Raichelis, R. (2013). Proteção Social e trabalho do assistente social: tendências e disputas na conjetura de crise mundial. Serviço Social e Sociedade, (116). 
Rocha, R. (2012). Cartografias urbanas: método de exploração das cidades na contemporaneidade. En Diez Tetamanti, J. M.; Escudero, B. (Comps.). Cartografía Social. Investigación e intervención desde las ciencias sociales, métodos y experiencias de aplicación. Editorial Universitaria de la Patagonia.

Rosso, I. (2018). Buenos Aires indígena. Cartografía social de lo invisible. UNICEN.

Rosso, I,; Escurra, M.; Leguizamón, A.; De Ávila, V.; Suarez, R.; Hiese, M.; Garcia, F. y Lanusse, L. (2019). Nuestro mapa. Diagnóstico participativo por medio de cartografía social. Informe técnico inédito. FCH, UNCPBA. http://www.fch.unicen.edu.ar/wp-content/uploads/2019/11/Informe-T\%C3\%A9cnico-NuestroMapa.pdf

Rosso, I. y Escurra, M. (2019). Nuestro mapa: Debates y desafíos en torno al mapeo colectivo desde el Trabajo Social y la Geografía. En Actas de Congreso XXI Jornadas de Geografía de la UNLP, 9 al 11 de octubre de 2019, Facultad de Humanidades y Ciencias de la Educación, Universidad Nacional de La Plata. http://www. memoria.fahce.unlp.edu.ar/trab_eventos/ev.13639/ev.13639.pdf

Risler, J. y Ares, P. (2013). Manual de mapeo colectivo: recursos cartográficos críticos para procesos territoriales de creación colaborativa. Tinta Limón.

Seemann, J. (2010). Cartografia e cultura: abordagens para a geografia cultural. Em Rosendahl, Z;; Corrêa, R. L. (Orgs.). Temas e caminhos da geografia cultural. EdUERJ.

Stolkiner, A. (1999). La Interdisciplina: entre la epistemología y las prácticas. El Campo Psi. http://www.campopsi.com.ar/lecturas/stolkiner.htm

Torres Carrillo, A. (2019). La sistematización como investigación participativa. En Paño Yáñez, P.; Rébola, R. y Suárez Elías, M. (Comps.). Procesos y Metodologías Participativas. Reflexiones y experiencias para la transformación social. CLACSO-UdelaR.

Valente Ezcurra, D. (2018). Políticas públicas, conflictos y estrategias de organización por el acceso al hábitat urbano en Tandil en la Historia Reciente. En Actas de Congreso, X Jornadas de Sociología de la UNLP, 5 al 7 de diciembre, Facultad de Humanidades y Ciencias de la Educación, Universidad Nacional de La Plata. http:// www.memoria.fahce.unlp.edu.ar/trab_eventos/ev.11786/ev.11786.pdf

Vapñarsky, C. A. y Gorojovsky, N. (1990). El crecimiento urbano en la Argentina. Grupo Editor Latinoamericano, IIED América Latina.

Vieira de Almeida, E. T. (2006). A sociedade civil e os seus múltiplos significados no debate contemporâneo: uma leitura gramsciana. Tesis de doutorado em Servico Social, Programa de Pos- Graduação, Centro de Filosofia e Ciências Humanas, Universidade Federal do Rio de Janeiro. 